Voix et Images

voixetimages

\title{
Le Dictionnaire pratique des auteurs québécois
}

\section{Robert Mélançon}

Volume 2, numéro 2, décembre 1976

Paul Chamberland

URI : https://id.erudit.org/iderudit/200059ar

DOI : https://doi.org/10.7202/200059ar

Aller au sommaire du numéro

\section{Éditeur(s)}

Les Presses de l'Université du Québec

\section{ISSN}

0318-9201 (imprimé)

1705-933X (numérique)

Découvrir la revue

Citer cet article

Mélançon, R. (1976). Le Dictionnaire pratique des auteurs québécois. Voix et Images, 2(2), 279-281. https://doi.org/10.7202/200059ar d'utilisation que vous pouvez consulter en ligne.

https://apropos.erudit.org/fr/usagers/politique-dutilisation/ 


\section{Le Dictionnaire pratique des auteurs québécois}

La publication du Dictionnaire pratique des auteurs québécois ${ }^{1}$ fera date. II s'agit d'un remarquable instrument de travail dont la consultation s'avérera indispensable pour tous les chercheurs en domaine québécois. Enfin, sous une forme maniable, "pratique " comme l'indique justement le titre, nous disposons d'une véritable somme de renseignements essentiels sur l'ensemble des écrivains québécois. Le DPAQ (on me permettra de proposer cette abréviation) est à la fois un dictionnaire biographique et critique des auteurs et une substantielle bibliographie des lettres québécoises. Les articles, clairs et bien informés, n'omettent en général rien d'essentiel et caractérisent brièvement l'cuvre en citant le plus souvent une étude due à un spécialiste. II y aurait par endroits des proportions à rétablir: fallait-il, par exemple, faire place à tant de théologiens ou accorder 144 lignes à Eva Kushner quand 37 lignes suffisent pour PaulMarie Lapointe dans un article qui est d'ailleurs un modèle du genre? L'ensemble reste toutefois très bon et relativement équilibré: $A$ chaque article s'ajoute une bibliographie divisée en deux sections: celle des "œuvres" rassemble, en ordre chronologique, les titres de tous les livres de l'auteur et des principaux textes qu'il a publiés dans des périodiques, revues ou journaux; celle des «études» propose un choix substantiel d'ouvrages et d'articles critiques. Il faut souligner que ces choix d'études sont vraiment substantiels et qu'on y trouve autant ou plus même de renseignements que dans les bibliographies d'ouvrages «spécialisés". Quelques comparaisons à titre d'exemples: J.-P Boucher dans les "Contes" de Jacques Ferron (L'Aurore, 1974), cite 19 études, le DPAQ en cite 20; E. Kushner (Saint-Denys Garneau, Seghers, 1967) et R. Vigneault (SaintDenys Garneau à travers Regards et jeux dans l'espace, PUM, 1973) citent respectivement 15 et 19 études, le $D P A Q, 22$; enfin, exemple spectaculaire, le $D P A Q$ énumère 51 études sur l'œuvre d'Anne Hébert alors que le livre récent de J.-L. Major (Anne Hébert et le mystère de la parole, PUM, 1976) n'en nomme que 22. Les bibliographies du DPAQ ne sont ni ne peuvent évidemment être complètes, mais elles rassemblent presque tout ce qui vaut d'être retenu sur chaque auteur et forment ainsi la plus complète et la plus utilisable bibliographie générale des lettres québécoises.

Aucun dictionnaire ne peut prétendre à l'exhaustivité. Le DPAQ offre une large sélection de «quelque six cents auteurs" (p. ix), un auteur québécois étant défini comme "celui qui par ses écrits a contribué à enrichir, au sens large du terme, la civilisation de la Nouvelle-France d'abord, 
du Canada français en général, du Québec en particulier " (p.x). Outre les poètes, romanciers, dramaturges, essayistes, se trouvent inclus dans cette définition des journalistes, des critiques, des historiens, des linguistes, des sociologues, des théologiens... Ce parti tient à la nature même du domaine littéraire québécois. Comme l'a signalé G.-A. Vachon, «le mot littérature, quand il passe du domaine français au domaine québécois, change de sens. Là, il englobe un certain ensemble d'œuvres incontestablement valables. Ici, il désigne la collection matérielle des œuvres produites dans les limites d'un territoire national ${ }^{2}$. On ne s'étonnera donc pas de trouver plus d'écrivants que d'écrivains et plus de versificateurs que de poètes dans le DPAQ. II n'en sera que plus utile puisqu'on ne consulte pas un répertoire de ce genre seulement ni d'abord pour se renseigner sur les écrivains les plus célèbres, ceux au sujet desquels une abondante information est déjà accessible ailleurs, mais pour trouver ce qui ne figure pas dans des ouvrages moins spécialisés. Le rôle du DPAQ n'est pas d'établir un palmarès mais de rassembler une documentation aussi abondante que possible. Il y réussit dans l'ensemble de façon remarquable.

Malgré le grand nombre d'auteurs retenus, il a fallu choisir et certaines absences, oublis ou exclusions, restent discutabies. Du côté des ancêtres de la Nouvelle-France, par exemple, on ne trouve rien sur Sceur Marie Morin, pourtant «le premier chroniqueur de la vie domestique et des événements familiers qui soit né au Canada ${ }^{3}$ ", rien non plus sur Louis Jolliet ou sur Nicolas Perrot. Pour les écrivains les plus récents, la sélection s'avère presque impossible et ne peut pas aller sans une part d'arbitraire. Malgré cette difficulté, les rédacteurs du DPAQ ont pris le risque d'accorder "une attention spéciale au présent" (p.xii), ce qui ne contribue pas peu à l'intérêt de leur ouvrage. Là aussi on regrette certaines absences: François Charron et Pierre Nepveu, les poètes les plus intéressants peut-être à s'être manifestés ces dernières années, méritaient sûrement un article autant qu'André Beaudet, Claude Beausoleil ou Serge Monast. On pourrait bien sûr chercher et trouver d'autres "oubliés", mais ce serait une entreprise stérile. Le DPAQ ne veut pas être absolument complet et c'est heureux. II faut savoir gré à ses auteurs d'avoir limité leur projet de façon à ce qu'il devienne réalité dans des délais raisonnables: un ouvrage presque complet, qui a le mérite d'exister et qui rendra d'inestimables services, vaut mieux qu'un projet utopique qui ne servira à rien parce qu'il ne pourra jamais voir le jour. Ils ont la modestie de présenter leur travail comme «la première étape d'une grande et difficile entreprise" et se proposent d'en faire paraître "périodiquement de nouvelles éditions, revues, corrigées, complétées et enrichies de la production littéraire courante" (p. xii). Il faut souhaiter que cette mise à jour régulière s'avère possible. Mais, c'est là l'essentiel, le DPAQ est dans sa forme actuelle un excellent ouvrage de référence, extrêmement riche et d'une consultation aisée, sans équivalent dans son domainè. En rendant ainsi acces- 
sible pour la première fois une telle somme d'informations, il suscitera sans doute un véritable renouvellement des études littéraires québécoises.

Robert Mélançon

Université de Montréal

1. A. Hamel, J. Hare et P. Wyczynski, Dictionnaire pratique des auteurs québécois, Montréal, Fides, 1976 , xxvi et $726 \mathrm{p}$.

2. G.-A. Vachon, "le Domaine littéraire québécois en perspective cavalière", Histoire de la littérature française du Québec sous la direction de P. de Grandpré, Montréal, Beauchemin, 1967, tome I, p. 27.

3. L. Mailhot, la Littérature québécoise, Paris, PUF, 1974, p. 12. 